\title{
METRÓPOLE E EXPANSÃO URBANA a persistência de processos "insustentáveis"
}

\author{
Marta Dora Grostein \\ Arquiteta e Urbanista, Professora de Graduação e Pós-Graduação da Faculdade de Arquitetura e Urbanismo da USP e \\ do Programa de Pós-Graduação em Ciência Ambiental da USP
}

\begin{abstract}
Resumo: O padrão de urbanização brasileiro imprimiu às metrópoles pelo menos duas fortes características associadas ao modo predominante de "fazer cidade": apresentam componentes de "insustentabilidade" vinculados aos processos de expansão e transformação urbana e proporcionam baixa qualidade de vida a parcelas significativas da população. Esse padrão cria um espaço dual: de um lado, a cidade formal, que concentra os investimentos públicos e, de outro, seu contraponto absoluto, a cidade informal, que cresce exponencialmente na ilegalidade urbana, sem atributos de urbanidade, exacerbando as diferenças socioambientais. A transformação urbana desses espaços implica processos amplos que extrapolam as práticas correntes de regularização de parcelamentos ou urbanização de favelas.

Palavras-chave: transformação urbana; meio ambiente; cidades e políticas públicas.
\end{abstract}

$\mathrm{O}$ estágio atual do crescimento metropolitano tem como característica marcante a importância assumida pela dimensão ambiental dos problemas urbanos, especialmente os associados ao parcelamento, uso e ocupação do solo, com relevante papel desempenhado pelos assentamentos habitacionais para população de baixa renda.

O processo de urbanização brasileiro, na segunda metade do século XX, conduziu à formação de 12 regiões metropolitanas e 37 aglomerações urbanas não-metropolitanas, que concentram $47 \%$ da população do país. Nas 12 áreas metropolitanas, residem $33,6 \%$ da população brasileira $(52,7 \mathrm{mi}-$ lhões de habitantes), em extensos conglomerados que envolvem 200 municípios (Ipea/Unicamp-IE-Nesur/IBGE, 1999). ${ }^{1}$ Esses complexos metropolitanos compreendem municípios com funções complementares, gestão independente ${ }^{2} \mathrm{e}$ capacidade financeira desigual. Estas características dificultam e condicionam o atendimento das demandas sociais e de infraestrutura urbana que, na maioria dos casos, surgem da relação funcional entre municípios e dependem de soluções que extrapolam seus limites político-administrativos, equacionando-se na escala regional. As regiões metropolitanas, por contingência ou natureza das relações estabelecidas entre municípios que a compõem, dependeriam de políticas integradas de desenvolvimento urbano e de ações articuladas, que seriam próprias de uma gestão compartilhada. Pela ausência histórica de procedimentos desse tipo, agravaram-se as inadequações no uso e ocupação do solo com forte impacto ambiental.

Na década de 80 , as periferias das nove regiões metropolitanas cresceram $3,1 \%$, enquanto o município-sede apresentou índices da ordem de 1,4\% (Ipea, 1997:190). Este crescimento ocorreu apesar de o processo de metropolização ter-se atenuado, com a taxa de crescimento populacional passando de $3,8 \%$, na década de 70 , para $2 \%$. Ainda assim, as metrópoles absorveram $30 \%$ do crescimento demográfico do país na década de 80 , recebendo 8,3 milhões de novos moradores (Ipea, 1997:190-191). Para o mesmo período, os dados do IBGE apontam índices significativos de crescimento da população residente em favelas $(118,33 \%)$ e de domicílios situados em favela $(133,19)$, destacando-se o aumento nas regiões de Belém, Recife, Curitiba e São Paulo. No município do Rio de Janeiro, $17,6 \%$ da população é favelada, ocupando os morros que margeiam a cidade. Em Natal, $9,54 \%$ da população do município mora em favelas, ocupando áreas de preservação ambiental, como dunas $(33,33 \%)$ mangues $(17,39 \%)$ e encostas $(5,79 \%)$. Também aglomerações urbanas mais recentes, como a de Campinas, registram no município-sede $7,98 \%$ da população residindo em favelas. Curitiba, cidade referência no que diz respeito à implantação de um sistema de planejamento e controle do uso e ocupação do solo tem, em sua região metropolitana, 8,53\% da população em favelas (Ipea/Infurb, 1998:89-91). 
No Município de São Paulo, 19,80\% da população mora em favelas, na beira de córregos, encostas íngremes, margens de avenidas e sob viadutos. No início dos anos 70, esse índice era de apenas $1 \%$, comparação expressiva que confirma a redução de alternativas de acesso à moradia para as populações de baixa renda. O agravamento da informalidade nas décadas recentes pode ser avaliado tanto pela diminuição da oferta de loteamentos legais quanto pelo seu contraponto: a oferta crescente de loteamentos irregulares e clandestinos na área de proteção aos mananciais. Entre 1988 e 1994, foram implantados 19,64 milhões de $\mathrm{m}^{2}$ e 100 mil lotes nessa região, sendo que em 1987 a população favelada já ultrapassava 120 mil pessoas, que ocupavam principalmente as áreas livres de loteamentos populares (Ipea/Infurb, 1998:89-91). Entre 1980 e 1995, a população na área protegida da Bacia do Guarapiranga praticamente dobrou, passando de 336.935 habitantes - inicialmente concentrados na região sul do $\mathrm{Mu}$ nicípio de São Paulo (69,9\%) - para 622.489 habitantes, com redução do índice mencionado $(67,4 \%)$, o que confirma o espraiamento da ocupação ilegal para outros municípios da bacia, como Itapecerica da Serra, Embu e Embu-Guaçu, que também dobraram de população no período mencionado (CNEC, 1997).

Verificam-se, nas metrópoles, um agravamento das condições de moradia das populações pobres - um processo de "periferização" do crescimento metropolitano (Ipea, 1997:190-191), acompanhado de um aumento significativo nos índices de favelização - e um grau devastador de degradação ambiental provocado por loteamentos ilegais e ocupações sobre áreas protegidas e solos frágeis. Fenômenos originalmente circunscritos ao município-sede reproduzem-se em outros que compõem a região metropolitana, geralmente municípios-dormitório (Meyer et alii, 1998).

\section{A "INSUSTENTABILIDADE" DO PADRÃO DE URBANIZAÇÃO METROPOLITANO}

O padrão de urbanização imprimiu às metrópoles apesar das especificidades regionais - ao menos duas fortes características associadas ao modo predominante de fazer "cidade": apresentam componentes de "insustentabilidade" associados aos processos de expansão da área urbana e de transformação e modernização dos espaços intra-urbanos; e proporcionam baixa qualidade de vida urbana a parcelas significativas da população. Em apenas quatro décadas - entre 1950 e 1990 - formaram-se 13 ci- dades com mais de um milhão de habitantes ${ }^{3} \mathrm{e}$ em todas elas a expansão da área urbana assumiu características semelhantes, isto é, não resultou de determinações ou projetos articulados visando a extensão da cidade, mas, ao contrário, prevaleceu a difusão do padrão periférico, condutor da urbanização do território metropolitano, perpetuando, assim, o loteamento ilegal, a casa autoconstruída e os distantes conjuntos habitacionais populares de produção pública, como seus principais propulsores.

A significativa concentração da pobreza nas metrópoles brasileiras tem como expressão um espaço dual: de um lado, a cidade formal, que concentra os investimentos públicos e, de outro, o seu contraponto absoluto, a cidade informal relegada dos benefícios equivalentes e que cresce exponencialmente na ilegalidade urbana que a constitui, exacerbando as diferenças socioambientais. A precariedade e a ilegalidade são seus componentes genéticos $\mathrm{e}$ contribuem para a formação de espaços urbanos sem atributos de urbanidade.

$\mathrm{O}$ avanço da urbanização, sua escala e velocidade não constituem problema em si, não fosse o modo como ocorreu. Deve-se estar atento para esse processo, pois a sustentabilidade do aglomerado urbano/metropolitano, em sua componente físico-urbanística, relaciona-se com as seguintes variáveis: a forma de ocupar o território; a disponibilidade de insumos para seu funcionamento (disponibilidade de água); a descarga de resíduos (destino e tratamento de esgoto e lixo); o grau de mobilidade da população no espaço urbano (qualidade do transporte público de mas$\mathrm{sa}$ ); a oferta e o atendimento às necessidades da população por moradia, equipamentos sociais e serviços; e a qualidade dos espaços públicos. Dessa forma, as políticas que sustentam o parcelamento, uso e ocupação do solo e as práticas urbanísticas que viabilizam estas ações têm papel efetivo na meta de conduzir as cidades no percurso do desenvolvimento sustentado.

O termo genérico "cidade" tornou-se pouco preciso para expressar o sentido do que se produziu socialmente como espaço urbano ou expansão de "cidade" a partir dos anos 40. Desde então, procura-se adjetivar o termo para designar a resultante espacial do processo que deu forma às periferias metropolitanas. A expressão Cidade Clandestina ou Cidade Irregular define a forma abusiva do crescimento urbano sem controle, próprio da cidade industrial metropolitana, compreendendo os bairros relegados pela ação pública, a cidade dos pobres e dos excluídos, a cidade sem infra-estrutura e serviços suficientes, a cidade ilegal, ainda que legítima. Já na década de 30, na metrópole 
de São Paulo, havia a menção à existência de uma "cidade clandestina", termo utilizado para designar os espaços da cidade onde predominava o fenômeno da abertura de loteamentos sem licenças, registros ou alvarás fornecidos pela prefeitura e que, eventualmente, também apresentavam problemas fundiários, isto é, de titulação da propriedade. Para os urbanistas e engenheiros municipais, a "cidade clandestina" também designava espaços precários e sem qualidade urbanística e, para eles, a solução prescrita seria a aprovação de leis mais exigentes, como expressam em textos produzidos na década de 50 e 60 nas revistas especializadas. Nos anos 70 , diante da escalada dessa prática abusiva e da expansão e consolidação das periferias, a municipalidade de São Paulo, na tentativa de entender a natureza jurídica e administrativa desses empreendimentos diante da tarefa de regularizá-los, buscou um refinamento do universo classificado genericamente de "clandestino", sendo que o termo irregular passa a designar aqueles empreendimentos ilegais que, embora apresentados inicialmente aos órgãos competentes para aprovação, por alguma razão - administrativa, urbanística ou de registro - tornaram-se "irregulares" durante a implantação. A análise das práticas urbanísticas que consolidaram a cidade clandestina/irregular revela, como recorrente, a relação permissiva entre poder público e loteador, permeada pela tolerância à irregularidade e à clandestinidade. ${ }^{4}$

A dualidade verificada nos processos socioespaciais de construção da metrópole contemporânea manifesta-se no reconhecimento de uma cidade "formal" assumida pelo poder público, onde se concentram os investimentos urbanos de todo tipo, e de outra construída à sua margem, que tem no conceito cidade informal a expressão mais abrangente para designá-la, pois associa o fenômeno da expansão urbana ilegal ao da exclusão social. Nele está implícito o pressuposto de que o acesso à cidade se dá de modo diferenciado e que é sempre socialmente determinado, compreendendo o conjunto das formas assumidas pelos assentamentos ilegais: loteamentos clandestinos/irregulares; favelas; e cortiços. A "cidade informal” é uma realidade de longa data nas cidades brasileiras, especialmente nas metrópoles que tiveram seu crescimento acelerado, a partir dos anos 40 e 50, associado ao processo de industrialização brasileira, como São Paulo e Rio de Janeiro. Entretanto, metrópoles com crescimento mais recente - como Belém, Brasília, Natal e Campinas - apresentam padrão semelhante. A reprodução e a permanência desse padrão de urbanização apontam para a incapacida- de recorrente do Estado em controlar e fiscalizar o uso e a ocupação do solo e atuar como controlador, financiador ou provedor de moradia para as populações com menos recursos. No Município de São Paulo, esse processo também é a expressão da crise do modelo de instrumentos formulado na década de 70 , dominado pelo conceito de zoneamento urbano, ${ }^{5}$ que, ao invés de ampliarem benefícios para o conjunto da população, funcionaram como limitadores da oferta de moradias ou loteamentos no mercado regular. Mais do que difusores de padrões de qualidade urbana e ambiental, como pretendia o legislador, estes instrumentos contribuíram decisivamente para a escalada da ilegalidade urbana.

A evolução desse processo resultou no agravamento de práticas ambientais predatórias, gerando erosões do solo, enchentes, desabamentos, desmatamentos e poluição dos mananciais de abastecimento e do ar, que afetam o conjunto urbano e em especial as áreas ocupadas pela população de baixa renda, com perdas e deseconomias significativas para o funcionamento adequado do conjunto metropolitano. A força do padrão periférico de urbanização evidenciou: a negligência do Estado, em suas diferentes instâncias, com a construção das cidades e a formulação de uma política de desenvolvimento urbano; a ilegalidade como fator estrutural na dinâmica de expansão urbana das metrópoles brasileiras; o lote urbano precário, a casa na favela e o aluguel de um quarto em cortiços como as alternativas predominantes para resolver o problema de moradia dos pobres nas metrópoles; a ausência de uma política habitacional metropolitana; a insuficiente produção pública de moradias sociais em face da demanda; e o descaso absoluto da sociedade e do poder público com os problemas socioambientais decorrentes.

\section{O RECONHECIMENTO DOS ASPECTOS SOCIOAMBIENTAIS ASSOCIADOS À CIDADE INFORMAL}

Os problemas ambientais urbanos dizem respeito tanto aos processos de construção da cidade e, portanto, às diferentes opções políticas e econômicas que influenciam as configurações do espaço, quanto às condições de vida urbana e aos aspectos culturais que informam os modos de vida e as relações interclasses. Nas parcelas da cidade produzidas informalmente, onde predominam os assentamentos populares e a ocupação desordenada, a combinação dos processos de construção do espaço com as condições precárias de vida urbana gera 
problemas socioambientais e situações de risco, que afetam tanto o espaço físico quanto a saúde pública: desastres provocados por erosão, enchentes, deslizamentos; destruição indiscriminada de florestas e áreas protegidas; contaminação do lençol freático ou das represas de abastecimento de água; epidemias e doenças provocadas por umidade e falta de ventilação nas moradias improvisadas, ou por esgoto e águas servidas que correm a céu aberto, entre outros. A escala e a freqüência com que estes fenômenos se multiplicam nas cidades revelam a relação estrutural entre os processos e padrões de expansão urbana da cidade informal e o agravamento dos problemas socioambientais.

As questões ambientais urbanas adquiriram visibilidade no decorrer das décadas de 80 e 90 , impulsionadas pelos fóruns internacionais promovidos pelas Nações Unidas. Das mudanças verificadas na política dos assentamentos humanos, entre a conferência de Vancouver 1976 (Habitat I) e a de Istambul 1996 (Habitat II), destaca-se a importância reservada às cidades e metrópoles no contexto das nações e na aplicação do conceito de sustentabilidade, bem como a revisão da crença de que o Estado, através da produção em grande escala de moradias em conjuntos habitacionais, poderia produzir domicílios para os pobres nas cidades na quantidade necessária. A conferência do Rio de Janeiro, em 1992, ECO/92 (United Nations Conference on Environment and Development - UNCED - Rio 92), centrada nos problemas do meio ambiente e desenvolvimento, concluiu que $3 / 4$ do crescimento da população urbana mundial, na última década do século XX, será absorvido por cidades do Terceiro Mundo, e colocou em evidência as questões da pobreza urbana e do custo econômico e social da degradação ambiental urbana.

A Agenda 21, produto da conferência do Rio - ECO 92, e a Agenda Habitat estão pautando as políticas públicas e as práticas urbanas de diversas cidades e metrópoles. Entre as diretrizes aí formuladas, destacam-se: a idéia de desenvolvimento sustentado; a necessidade de coordenação setorial; a descentralização de tomada de decisões; e a participação das comunidades interessadas em instâncias específicas da gestão urbana. Estas diretrizes articulam desenvolvimento econômico, desenvolvimento social, desenvolvimento urbano e proteção ao meio ambiente, indicando os componentes gerais para o entendimento da noção de desenvolvimento urbano sustentado. O balanço entre "liberdade de construir", "dever de proteger" e "condições dignas de moradia para todos" é desejável e, para ser obtido, necessita-se de um governo ur- bano representativo. O governo é a arena em que todas as decisões sobre provisão precisam tomar lugar e, desta forma, ganha importância a montagem de estruturas eficientes para a tomada de decisões, apoiadas em políticas de desenvolvimento urbano e instrumentos regulamentados para o exercício dessa política.

O Habitat II identificou, como um dos principais obstáculos para alcançar o objetivo de assentamentos adequados para todos, a falha dos mercados e governos em colocar terra e financiamento suficientes e adequados em termos de preço, tempo e lugar. Os compromissos assumidos pelos governos, entre os quais o governo brasileiro, com a implementação das agendas mencionadas apontam para a importância do papel sinalizador de uma política urbana federal que apóie as ações locais nos estados, metrópoles e municípios da federação. As cidades são centrais para alcançar o desenvolvimento sustentado, uma vez que é onde se localiza a maior parte da atividade industrial, do transporte e da concentração de pessoas.

Se a "cidade informal", por um lado, tem sido solução do ponto de vista do assentamento dos pobres na cidade, por outro, gera problemas socioambientais que causam impactos ao ambiente com riscos significativos. A origem dos problemas ambientais urbanos deve ser diferenciada para se evitar o escamoteamento de problemas e responsabilidades e mesmo a generalização de soluções. Duas situações se destacam: os problemas resultantes de opções de obras e projetos realizados pelo poder público para estruturar o funcionamento das cidades; as questões associadas às estratégias de sobrevivência das populações com menos recursos nas cidades. No primeiro caso, a falta de uma política de desenvolvimento urbano-ambiental é evidente e acarreta disfunções no crescimento urbano: permite expansões desnecessárias da malha urbana de acordo com o interesse dos diferentes mercados imobiliários (o formal e o informal); dissocia expansão urbana da oferta de transporte público; e possibilita construção aleatória e por vezes inadequada de sistema viário, ocupando fundos de vale e impermeabilizando áreas de várzea. A expansão urbana sem transporte público metropolitano de massa eficiente é um caminho explosivo do ponto de vista da qualidade de vida nas metrópoles e aglomerações urbanas, assim como a impermeabilização descontrolada do solo com pavimentação, sem projetos de macrodrenagem. Por outro lado, a degradação ambiental associada às estratégias de sobrevivência das populações de menores recursos nas cidades tem origem nas condições socioeconômicas e na falta de opções de moradia acessíveis no 
mercado formal, conforme mencionado anteriormente, implicando a formulação de políticas sociais de inclusão urbana.

A opção de desenvolvimento predominante contribuiu para a consolidação de irracionalidades no uso e ocupação do solo, transformando fundos de vale em avenidas, áreas protegidas em loteamentos, ocupando várzeas, desconsiderando o território e perpetuando as enchentes. A responsabilidade pública é evidente. Em um contexto de escassez de recursos, os investimentos em todas as instâncias de governo e o aval a financiamentos têm que se pautar em prioridades definidas no quadro de uma política de desenvolvimento urbano-ambiental. Noções abrangentes e abstratas como o de "desenvolvimento urbano sustentável" são referências condutoras de políticas e práticas, devendo ser flexíveis e socialmente construídas, isto é, resultantes da compreensão dos conflitos e embates presentes nos processos de expansão e transformação urbana. Desse modo, poderão influenciar a formulação de políticas públicas para a construção de um ambiente urbano equilibrado e justo. Diante de questões geradas eminentemente na esfera socioeconômica, as políticas públicas formuladas e assumidas têm um papel fundamental na distribuição dos benefícios urbanos gerados por obras públicas e na justiça social definida pela democratização dos acessos a todas as esferas da vida urbana, especialmente a uma moradia digna.

\section{O Processo de Transformação da Cidade Informal}

A força que a questão ambiental adquiriu na última década coloca novo referencial e responsabilidades para a tarefa de regularização de loteamentos e urbanização de favelas em face dos conflitos socioambientais que provocam. A questão da incorporação da cidade informal e a requalificação de áreas degradadas passam a ser mediadas e relativizadas pelos interesses difusos da população metropolitana, como a necessidade de preservar a qualidade da água dos mananciais de abastecimento, ou a de defender as áreas de proteção ambiental, ou mesmo a defesa de parques urbanos ou espaços verdes. O conflito entre a defesa desses interesses e o direito social de acesso a uma moradia evidencia a urgência no contexto metropolitano de programas de reconstrução das periferias, que compreendam programas de inclusão social e econômica dessas populações e, evidentemente, de ações específicas que, por um lado, facilitem o acesso a financiamentos desenhados para atender às características dessas populações metropolitanas e, por outro, estimulem a produção de moradias acessíveis no mercado formal.

A partir de fins da década de 70 e início dos anos 80 , criaram-se condições políticas e sociais favoráveis para processos de revisão das normas e formulação de instrumentos urbanísticos que permitam atuar em contextos urbanos de origem ilegal. O reconhecimento tardio da cidade informal, bem como sua incorporação como questão de governo, ocorre paralelamente às novas dinâmicas que acompanham a abertura democrática e as discussões dos parâmetros da nova constituição brasileira e culmina com sua promulgação em 1988. Ganham novo respaldo jurídico instrumentos como as "zonas especiais de interesse social", o "usucapião urbano", ou a "concessão do direto real de uso", que ampliam as possibilidades de ação pública e, combinados, permitem alterar o foco de atuação nas áreas informais, excessivamente centrado em medidas de cunho jurídico administrativo - predominante nas políticas de regularização de loteamentos - para o campo das políticas públicas mais amplas de inclusão social e econômica e urbanística dos moradores dos assentamentos ilegais. De normas genéricas de parcelamento do solo urbano, passa-se a um refinamento na abordagem dos instrumentos. Hoje, a incorporação da cidade produzida fora das normas é tarefa pública, processo em andamento com maior ou menor grau de eficiência nas diferentes cidades desde o final da década de 80 , com resultados significativos em cidades como Recife e Diadema, ou mais recentemente em programas como "Favela Bairro", no Rio de Janeiro.

Para a incorporação da cidade informal, que tem início com a política de regularização em massa de loteamentos na década de 80 , foi necessária a montagem de novas estruturas especiais, paralelas às existentes, bem como o desenvolvimento de uma cultura pública diferenciada, na busca de identificar caminhos para agir sobre espaços ilegais e complexos. Esta tarefa inverte o esquema tradicional de ação do poder público sobre o uso e ocupação do solo - aquela que se inicia tradicionalmente como controlador na análise e aprovação de projetos -, passando a atuar sobre realidades construídas que não se enquadram nas normas de parcelamento do solo e exigem portanto novo respaldo jurídico e social. Os embates ocorrem pelos conflitos que emergem entre as estruturas tradicionais e a mentalidade que as sustentam, com a instalação de novas práticas. No caso da regularização de loteamentos, a eficiência depende de análises integradas e ações específicas de naturezas diferentes, mas conco- 
mitantes. Regularizar a titulação dos lotes depende da regularização urbanística do empreendimento que, por sua vez, depende de negociações com o loteador omisso e assim por diante, em uma cadeia de situações que precisam ser identificadas caso a caso. A solução individual é fundamental para o encaminhamento da regularização fundiária e administrativa, mas insuficiente para a solução dos problemas urbanísticos do loteamento e suas áreas vizinhas, o que constitui um dilema a ser equacionado. A regularização em favelas traz questões de integração urbanística semelhantes, embora do ponto de vista da regularização fundiária envolva problemas de natureza diversa da mencionada para os loteamentos, pois trata-se geralmente da regularização de ocupações em áreas públicas invadidas e o instrumento utilizado tem sido a concessão do direito real de uso.

Ao longo da década de 80 , ocorreram transformações significativas no âmbito da ação do poder público sobre os espaços informais, quando se buscaram novos caminhos de atuação e tornou-se explícita a incorporação desse tema como questão de governo a ser enfrentada por meio da formulação e implementação de políticas públicas específicas. São marcos significativos desse percurso o início da década, com a política precursora de regularização em massa de loteamentos formulada e institucionalizada na cidade de São Paulo em 1979/81, e o final dos anos 80, quando a cidade de Recife ${ }^{6}$ inovou significativamente ao introduzir na legislação de uso e ocupação do solo de 1983 o conceito de Zonas Especiais de Interesse Social (Zeis). Entretanto, sua aplicação de fato ocorreu em 1987, com a promulgação do Plano de Regularização de Zonas Especiais de Interesse Social (Prezeis). Esse instrumento permite atuar de forma mais efetiva e integrada sobre os espaços produzidos informalmente, promovendo a regularização dessas áreas - urbanística, registrária e administrativa -, bem como garantir a reserva de novas áreas com localização adequada para futuro uso habitacional por população de baixa renda. Instrumento semelhante foi criado, em 1994, na Região Metropolitana de São Paulo. Esses instrumentos reforçam a base legal para uma ação regularizadora da ocupação de áreas públicas e particulares (Ipea/Infurb, 1998).

Os problemas ambientais urbanos nas cidades brasileiras não são novos, entretanto, o que está mudando é a consciência social de que muitos deles poderiam ser evitados e a importância que a solução desses problemas assume para a sociedade. Em um território urbanizado, onde prevalecem a escassez de terra adequada e acessível para o assentamento das populações de baixa renda e a precariedade nas periferias em um quadro de exclusão e pobre$\mathrm{za}$, dificilmente poderão ser equacionados os problemas ambientais, sem uma política habitacional.

Construir "cidade" é tarefa social complexa, que requer investimentos públicos e privados, projetos e programas de intervenção e justiça na distribuição dos benefícios urbanos. Não basta abrir ruas e parcelar glebas em lotes, assim como para introduzir qualidade ambiental na cidade informal não basta regularizar loteamentos ou urbanizar as favelas.

Entretanto, a grande dificuldade nos processos de integração da cidade informal na cidade propriamente dita está no fato de a regularização fundiária e urbanística não ser suficiente para a integração social e econômica destas áreas. Os programas devem promover a possibilidade de combinação de ações econômicas, sociais, urbanísticas e ambientais e, principalmente, deslocar a ótica da atuação pública: de um loteamento ou favela, para a reconstrução de bairros precários; do proprietário do lote, para a comunidade beneficiada. Enfim, atender aos interesses dos moradores e à necessidade dos bairros, condicionados pelos interesses difusos da população e da cidade.

\section{NOTAS}

E-mail da autora: martagrostein@uol.com.br

1. A rede urbana, de acordo com o estudo mencionado, está formada por: metrópoles globais, nacionais ou regionais; centros regionais; e centros sub-regionais, que comandam uma rede de municípios onde residem $78,4 \%$ da população brasileira. Esta diversificação formou-se em poucas décadas, pois, uma condição basicamente rural verificada nos anos 50 - com $36 \%$ de população urbana - passouse para outra predominantemente urbana.

2. São Paulo (39 municípios); Rio de Janeiro (21 municípios); Salvador (11 municípios); Belo Horizonte (25 municípios); Fortaleza (11 municípios); Brasília (10 municípios); Curitiba (16 municípios); Recife (16 municípios); Porto Alegre (24 municípios); Belém (4 municípios); Goiânia (6 municípios); e Campinas (17 municípios).

3. Em 1950, o Brasil tinha apenas duas cidades com mais de 1 milhão de habitantes: São Paulo e Rio de Janeiro.

4. Para maior aprofundamento da questão relacionada à clandestinidade e à irregularidade nos loteamentos na cidade de São Paulo, consultar (Grostein, 1987).

5. O zoneamento urbano confere tratamento homogêneo, isto é, regras similares para situações urbanas desiguais, e exigências genéricas como infra-estrutura completa em todos os loteamentos com lote mínimo inicialmente fixado em $250 \mathrm{~m}^{2}$, passando a seguir para $125 \mathrm{~m}^{2}$. Estas determinações independem tanto do tipo de empreendimento quanto da capacidade de acesso das populações a eles.

6. No Recife, a lei de uso do solo de 1983 instituiu legalmente as Zonas Especiais de Interesse Social definidas como "assentamentos habitacionais surgidos espontaneamente, existentes e consolidados onde são estabelecidas normas urbanísticas especiais, no interesse social de promover a sua regularização jurídica e sua integração na estrutura urbana". O Plano de Regularização de Zonas Especiais de Interesse Social (Prezeis) foi instituído pela Lei $\mathrm{n}^{\circ}$ 14.947/87 que, "apesar de chamado de Plano representa uma política formulada com o objetivo de enfren$\operatorname{tar}($...) a questão da habitação e do acesso à terra para a população de baixa renda" (Ipea/UFPE, 1997:84). 


\section{REFERÊNCIAS BIBLIOGRÁFICAS}

CNEC. JNS-Engenharia, Consultoria e Gerenciamento S/C Ltda. Plano de desenvolvimento e proteção ambiental da Bacia do Guarapiranga-PDPA. Diagnóstico ambiental. São Paulo, jan. 1997.

GROSTEIN, M.D. A cidade clandestina: os ritos e os mitos. O papel da irregularidade na estruturação do espaço urbano no Município de São Paulo 1900/1987. Tese de doutorado. São Paulo, FAUUSP, 1987.

IPEA - Instituto de Pesquisa Econômica Aplicada. O Brasil na virada do milênio. Trajetória do crescimento e desafio do desenvolvimento. Brasília, 1997.

Gestão do uso do solo e disfunções do crescimento urbano. Avaliação e recomendações para a ação pública. Brasília, 1998, mimeo.

IPEA/INFURB - Instituto de Pesquisa Econômica Aplicada e Núcleo de Pesquisas em Informações Urbanas. Gestão do uso do solo e disfunções do cresci- mento urbano. Avaliação dos instrumentos de planejamento e gestão do uso do solo na Região Metropolitana de São Paulo. Brasília, Relatório 2 , 1998, mimeo.

IPEA/UFPE. Instituto de Pesquisa Econômica Aplicada/Mestrado em Desenvolvimento Urbano e Regional. Gestão do uso do solo e disfunções do crescimento urbano. Avaliação dos instrumentos de planejamento e gestão do uso do solo na Região Metropolitana de Recife. Relatório 2. Brasília, 1997, mimeo.

IPEA/UNICAMP-IE-NESUR/IBGE. Caracterização e tendências da rede urbana do Brasil. Campinas, Unicamp (Coleções Pesquisas, 3), 1999.

MEYER, R.P.; LEME, M.C.; GROSTEIN, M.D. e BIDERMAN, C. "São Paulo Metrópole Terciária. Entre a modernização pós-industrial e a herança social e territorial da industrialização”. São Paulo, FAUUSP/Ipea/Cebrap, Relatório Final, 1998 , mimeo. 